Portland State University

PDXScholar

8-6-2008

\title{
Synthesis and Relaxometric Studies of a Dendrimer-Based pH-Responsive MRI Contrast Agent
}

\author{
M. Meser Ali \\ University of Texas at Dallas \\ Mark Woods \\ Portland State University, mark.woods@pdx.edu \\ Peter Caravan \\ A.A. Martinos Center for Biomedical Imaging \\ Ana C.L. Opina \\ University of Texas at Dallas \\ Marga Spiller \\ New York Medical College
}

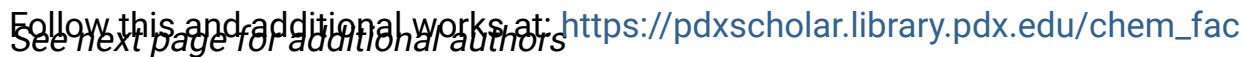

Part of the Chemistry Commons

Let us know how access to this document benefits you.

\section{Citation Details}

Ali, M. M., Woods, M., Caravan, P., Opina, A. C., Spiller, M., Fettinger, J. C., \& Sherry, A. D. (2008). Synthesis and relaxometric studies of a dendrimer-based $\mathrm{pH}$-responsive MRI contrast agent. Chemistry-A European Journal, 14(24), 7250-7258.

This Post-Print is brought to you for free and open access. It has been accepted for inclusion in Chemistry Faculty Publications and Presentations by an authorized administrator of PDXScholar. Please contact us if we can make this document more accessible: pdxscholar@pdx.edu. 


\section{Authors}

M. Meser Ali, Mark Woods, Peter Caravan, Ana C.L. Opina, Marga Spiller, James C. Fettinger, and A. Dean Sherry 


\title{
Synthesis and Relaxometric Studies of a Dendrimer-Based pH- Responsive MRI Contrast Agent
}

\author{
M. Meser Alia , Mark Woods a,b, Peter Caravan [Prof.] ${ }^{C}$, Ana C. L. Opina ${ }^{a}$, Marga Spillerd, \\ James C. Fettingere, and A. Dean Sherry [Prof.] ${ }^{a}, f$ \\ M. Meser Ali: ; Mark Woods: ; Peter Caravan: ; Ana C. L. Opina: ; Marga Spiller: ; James C. Fettinger: ; A. Dean Sherry: \\ dean.sherry@utsouthwestern.edu \\ aDepartment of Chemistry, University of Texas at Dallas, P.O. Box 830660, Richardson, Texas \\ 75083 (USA) \\ bMacrocyclics, 2110 Research Row, Suite 425, Dallas, Texas 75235 (USA)
}

${ }^{\mathrm{C} A . A . ~ M a r t i n o s}$ Center for Biomedical Imaging, Department of Radiology, Massachusetts General Hospital and Harvard Medical School, Charlestown, MA 02129 (USA)

dDepartment of Radiology, New York Medical College, Valhalla, New York 10595 (USA)

eDepartment of Chemistry, University of California at Davis, One Shields Avenue, Davis, CA 95616-5298 (USA)

${ }^{f} A d v a n c e d$ Imaging Research Center, University of Texas Southwestern Medical Center, 5323 Harry Hines Boulevard, Dallas, Texas 75390 (USA), Fax: (+1) 214-645-2744

\section{Abstract}

The design of effective $\mathrm{pH}$ responsive MRI contrast agents is a key goal in the development of new diagnostic methods for conditions such as kidney disease and cancer. A key factor determining the effectiveness of an agent is the difference between the relaxivity of the "on" state compared to that of the "off" state. In this paper, we demonstrate that it is possible to improve the $\mathrm{pH}$-responsive action of a low molecular weight agent by conjugating it to a macromolecular construct. The synthesis of a bifunctional $\mathrm{pH}$ responsive agent is reported. As part of that synthetic pathway we examine the Ing-Manske reaction, identifying an undesirable by-product and establishing effective conditions for promoting a clean and effective reaction. Reaction of the bifunctional $\mathrm{pH}$ responsive agent with a G5-PAMAM dendrimer yielded a product with an average of 96 chelates per dendrimer. The relaxivity of the dendrimer conjugate rises from $10.8 \mathrm{~mm}^{-1} \mathrm{~s}^{-1}\left(\mathrm{pH}\right.$ 9) to $24.0 \mathrm{~mm}^{-1} \mathrm{~s}^{-1}(\mathrm{pH}$ 6) per $\mathrm{Gd}^{3+}$ ion. This more than doubles the relaxivity $\mathrm{pH}$ response, $\Delta r_{1}$, of our agent from just $51 \%$ for the original low molecular weight chelate to $122 \%$ for the dendrimer.

\section{Keywords}

dendrimers; imaging agents; lanthanide complexes; MRI contrast agents 


\section{Introduction}

Diseases, such as kidney disorders and cancer, often result in a significant reduction in the extracelluar $\mathrm{pH}$ of these tissues.[1-3] Thus, imaging tissue $\mathrm{pH}$ could be quite useful in clinical diagnose of these and other conditions. Current methods for assessing tissue $\mathrm{pH}$ involve relatively invasive procedures and typically can assess $\mathrm{pH}$ only from a limited number of locations.[2-4] Less invasive techniques such as ${ }^{31} \mathrm{P}$ NMR NMR spectroscopy[4] can provide a direct measure of $\mathrm{pH}$ but the concentrations of the endogenous phosphorus metabolites that respond to tissue $\mathrm{pH}$ are relatively low so $\mathrm{pH}$ measurements can only be taken from relatively large volumes of tissue. $\mathrm{pH}$ sensitive fluorescence dyes are quite sensitive but applications of optical techniques in human imaging is limited to tissues near the surface of skin where sufficient light penetration can be achieved.[4] A pH responsive $T_{1}$-shortening contrast agent could offer a minimally invasive and highly practical approach to mapping of tissue $\mathrm{pH}$ so it is hardly surprising that a large number of $\mathrm{pH}$ sensitive MRI contrast agents have been reported. [5-13]

Typically, $\mathrm{Gd}^{3+}$-based complexes used to relax bulk water have relatively low $T_{1}$ relaxivities. Relaxivity is defined as the increase in water proton relaxation rate per unit concentration of contrast agent and is a measure of the effectiveness of a contrast agent. At typical magnetic fields used for clinical imaging, the relaxivity of a $\mathrm{Gd}^{3+}$ complex is primarily determined by three factors: $q$, the number of water molecules in the inner coordination sphere of $\mathrm{Gd}^{3+} ; \tau_{\mathrm{M}}$, the residence lifetime of these water molecule on $\mathrm{Gd}^{3+}$; and $\tau_{\mathrm{R}}$, the rotational correlation time, or how fast the complex tumbles in solution.[14-18] Examples of contrast agents that respond to $\mathrm{pH}$ through changes in each of these parameters have been reported,[5] but the only agent actually used to image tissue $\mathrm{pH}$ to date is $\mathrm{Gd} \mathbf{1}$ (see below).[12,13] Although Gd1 exhibits a relatively small a change in relaxivity over a physiologically relevant $\mathrm{pH}$ range, it has been used successfully in vivo to generate $\mathrm{pH}$ maps of kidneys and tumors in small animals.[1921] The mechanism by which $\mathrm{Gd} \mathbf{1}$ operates as a $\mathrm{pH}$ responsive agent is unique among responsive $\mathrm{Gd}^{3+}$ agents and stems from the presence of the phosphonate groups of the pendant arms.[12] The sole inner-sphere water molecule of Gd1 is in slow exchange with the bulk solvent which, ordinarily, would limit relaxivity. However, the phosphonate groups of $\mathrm{Gd} 1$ are able to catalyse the exchange of the protons of this single $\mathrm{Gd}^{3+}$-bound water molecule with bulk solvent protons. The effectiveness of the phosphonates at catalysing proton exchange is dependent upon their protonation state so as the four phosphonates become successively protonated at the $\mathrm{pH}$ falls below $\approx 8.5$, the rate of proton exchange increases and the paramagnetic relaxation effects of $\mathrm{Gd}^{3+}$ are transferred to the bulk solvent protons. In addition the phosphonates can organise a number of other water molecules into a second hydration sphere through hydrogen-bonding interactions.[22,23] The extent, and proton residence lifetime, of this second hydration sphere is also likely to fluctuate with the protonation state of the phosphonate groups. The increase in relaxivity of $\mathrm{Gd} 1$ on passing from $\mathrm{pH} 9$ to 6 was found to be the result of a combination of these two effects.[12] 


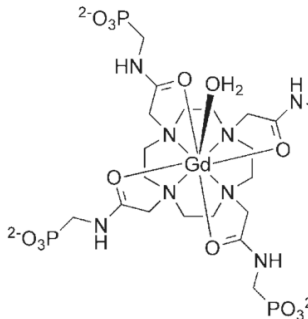

Gd1

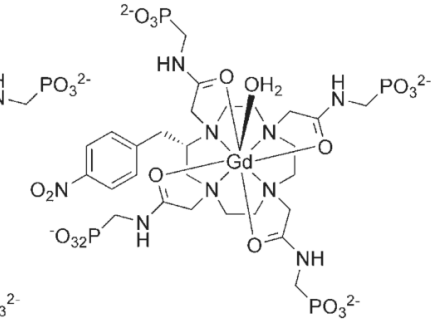

$\mathrm{Gd} 2$

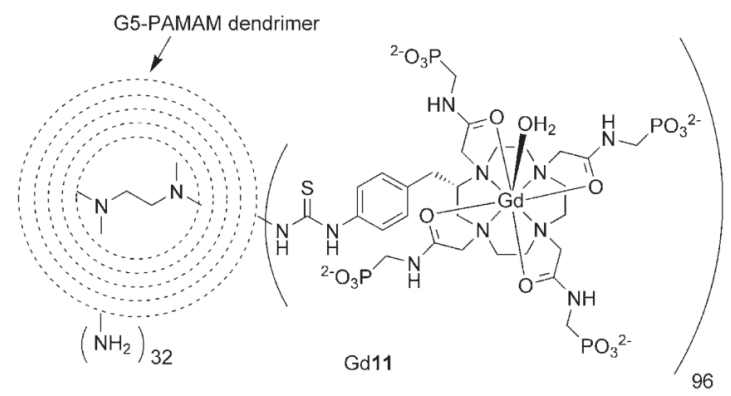

Despite the demonstrated utility of $\mathrm{Gd} \mathbf{1}$, the maximum increase in relaxivity with changing $\mathrm{pH}, \Delta r_{1}$, is relatively modest, rising from $3.5 \mathrm{~m}^{-1} \mathrm{~s}^{-1}$ at $\mathrm{pH} 9.5$ to $5.3 \mathrm{~mm}^{-1} \mathrm{~s}^{-1}$ at $\mathrm{pH} 6.3$; a $\Delta r_{1}$ of just $51 \%$.[12] The relaxivity arising from an exchanging inner-sphere water molecule, $r_{1}$ i.s., is given by Equation (1), where $\tau_{\mathrm{M}}$ is the lifetime of the inner-sphere bound water molecule and $T_{1 \mathrm{M}}$ is the $T_{1}$ of the inner-sphere water protons. The relaxivity arising from water molecules in the second hydration sphere follows a similar relationship. From Equation (1) it can be seen that relaxivity will be higher if $T_{1 \mathrm{M}}$ is shorter, but the rapid rotational dynamics of $\mathrm{Gd} 1$ cause $T_{1 \mathrm{M}}$ to be long thereby limiting relaxivity.

$$
r_{1}^{\text {i.s. }}=\frac{1}{55.6}\left(\frac{\mathrm{q}}{T_{1 \mathrm{M}}+\tau_{\mathrm{M}}}\right)
$$

Slowing molecular rotation is most easily achieved by conjugating the contrast agent to a macromolecule, such as a dendrimer. However, improving relaxivity alone will not improve the function of $\mathrm{Gd} \mathbf{1}$ as a $\mathrm{pH}$ responsive contrast agent. To do that it is necessary to accentuate the difference between the high and low relaxivity regimes. We hypothesized that $T_{1 \mathrm{M}}$ could be reduced by conjugating Gd1 to a dendrimer which would render the system more sensitive to changes in $\tau_{\mathrm{M}}$. At higher $\mathrm{pH}$ values, the relaxivity would be expect to be limited by slow exchange whereas at lower $\mathrm{pH}$ values, catalysis of inner-sphere proton exchange by the phosphonate groups should lift the limiting effect of exchange upon relaxivity $\left(T_{1 \mathrm{M}}>\tau_{\mathrm{M}}\right)$. Overall, coupling Gd1 to the dendrimer should improve both the absolute relaxivity, $r_{1}$, and the change in relaxivity, $\Delta r_{1}$, on going from low to high $\mathrm{pH}$. We therefore set out to conjugate Gd1 to a larger macromolecule, in this case an ethylenediamine core G5-PAMAM dendrimer, in order to reduce the rate of rotation and improve the $\mathrm{pH}$ responsive characteristics of the complex.

\section{Results and Discussion}

\section{Synthesis}

As the phosphonate groups of the pendant arms were found to be responsible for the $\mathrm{pH}$ responsive nature of $\mathrm{Gd} \mathbf{1},[12]$ it was important to maintain this structural feature when the 
complex was modified to facilitate attachment to the dendrimer. Accordingly, the complex was modified by incorporating a functionalized benzyl group onto the macro-cyclic backbone of the complex, leaving the four phosphonate groups intact. The functionalized complex $\mathrm{Gd} \mathbf{2}$ was prepared following the same synthetic procedure used for the preparation of Gd1[12] simply substituting (S)-2-( $p$-nitrobenzyl) cyclen for cyclen (Scheme 1).

Compound $\mathbf{3}$ was prepared by the Michaelis-Arbuzov reaction of triethylphosphite with bromomethyl phthalimide. The key intermediate $\mathbf{4}$ was then obtained by removal of the phthalimide protecting group by an Ing-Manske[24] reaction with 1.2 equivalents of hydrazine in ethanol. Normally this type of deprotection reaction proceeds in good yields; [24] however, in our case the yields were moderate at best.[12] Furthermore, the presence of significant quantities of a reaction by-product meant that column chromatography was necessary to purify amine 4 , an oil at room temperature. Amines can often be purified by an acid/base extraction but 4 shows good water solubility, even at high $\mathrm{pH}$, and this precluded purification by extraction. Low yielding reactions that require complicated purification procedures are unsuitable for the scale-up necessary for the production of large quantities of an MRI contrast agent. We therefore undertook an investigation into the reasons for the low reaction yield of this step.

${ }^{1} \mathrm{H}$ NMR analysis of the crude reaction mixture indicated that the primary contaminant of the product $\mathbf{4}$ was a single reaction by-product. This compound was isolated by column chromatography and characterized. Rather surprisingly, this by-product was identified as compound $\mathbf{5}$, the product of a reaction between the starting material $\mathbf{3}$ and the intended reaction product 4 (Scheme 2). A significant effort has been applied to understanding the mechanism and intermediates of the Ing-Manske reaction,[25-28] however, this particular reaction pathway is rarely included in these discussions.[29] The quantities of $\mathbf{5}$ produced suggest that this side reaction may, on occasion, be more important than generally described. The mechanism of the Ing-Manske reaction is quite complex[26-29] but it is initiated by nucleophilic attack of hydrazine at one of the carbonyls of the phthalimide. The effectiveness of an amine at removing phthalimide protecting groups has been shown to relate to the protonation constant of the attacking amine; the more basic the amine, the more effective the reaction.[27] Thus, if the product amine is significantly more basic than hydrazine, it is likely to compete with hydrazine in attacking the phthalimide $\mathbf{3}$ to yield significant quantities of compound $\mathbf{5}$.

The identity of compound $\mathbf{5}$ was established by NMR spectroscopy and mass spectrometry and, although attempts to remove compound $\mathbf{5}$ from the crude reaction mixture by crystallisation were unsuccessful, compound $\mathbf{5}$ readily crystallises once purified. X-ray quality crystals could be grown at room temperature from a solution of $\mathbf{5}$ in dichloromethane by addition of diethyl ether and hexanes. This allowed the structure of compound $\mathbf{5}$ to be confirmed by X-ray crystallography (Figure 1). The production of compound $\mathbf{5}$ during the deprotection of the phthalimide $\mathbf{3}$ is doubly detrimental to the yield of $\mathbf{4}$ since two molecules of $\mathbf{4}$ are taken up into one molecule of $\mathbf{5}$; this is in addition to the need for chromatography. Thus, eliminating compound $\mathbf{5}$ from the reaction would both improve yield and simplify purification since the other reaction by-product, the insoluble phthalhydrazide, can be removed by filtration. A number of improvements to the Ing-Manske reaction have been suggested, most notably raising the reaction $\mathrm{pH}$ through addition of sodium hydroxide.[26,27] However, concerns over the lability of the phosphonate diester moiety towards base-catalysed hydrolysis precluded this as a solution to this problem. We investigated a number of the other Ing-Manske reaction conditions to assess whether the reaction conditions could be improved.

Compounds $\mathbf{4}$ and $\mathbf{5}$ are easily distinguished by ${ }^{1} \mathrm{H}$ NMR spectroscopy; a shift difference of almost $1 \mathrm{ppm}$ is observed for the methylene resonance $\alpha$ to the phosphorous. This resonance 
appears as a doublet at $2.9 \mathrm{ppm}$ (coupled to phosphorous) in $\mathbf{4}$ and as a doublet of doublets at $3.8 \mathrm{ppm}$ (coupled to phosphorous and the amide proton) in $\mathbf{5}$. A series of experiments were performed in which various reaction conditions were altered and the ratio of the two reaction products in the crude reaction mixture determined by ${ }^{1} \mathrm{H}$ NMR spectroscopy. Neither increasing the reaction temperature from room temperature to reflux nor increasing the reaction time from $6 \mathrm{~h}$ to $5 \mathrm{~d}$ was found to have a significant effect upon the distribution of reaction products. However, when the amount of hydrazine used in the reaction was increased the amount of $\mathbf{4}$ obtained from the reaction was greatly increased at the expense of $\mathbf{5}$. Increasing the amount of hydrazine from one to four equivalents greatly reduced the amount of $\mathbf{5}$ produced in the reaction. At six equivalents of hydrazine the yield of $\mathbf{5}$ was $<5 \%$, and ten equivalents of hydrazine eliminated all traces of 5 from the reaction ${ }^{1} \mathrm{H}$ NMR spectrum. This observation does not indicate that $\mathbf{5}$ is not produced during the reaction. Indeed, when an purified sample of 5 was treated with ten equivalents of hydrazine it was found to undergo a quantitative conversion to 4 , as determined by ${ }^{1} \mathrm{H}$ NMR (Scheme 2). Thus, 5 may still be produced in the reaction but, importantly, it is reactive under these conditions and does not persist as a reaction product.

Changing the conditions of the Ing-Manske reaction by increasing to ten the equivalents of hydrazine allowed purification to be simplified from column chromatography to filtration to remove the phthalhydrazide. It also improved the reaction yield to $97 \%$ and rendered this process suitable for scale-up. Condensation of the amine $\mathbf{4}$ with bromoacetyl bromide afforded the bromoacetamide 6 which was used to alkylate $(S)$-2-( $p$-nitrobenzyl) cyclen in acetonitrile with $\mathrm{K}_{2} \mathrm{CO}_{3}$ as base (Scheme 1). Subsequent deprotection of the phosphonate esters of 7 with $\mathrm{HBr}$ in $\mathrm{AcOH}$ afforded the ligand $\mathbf{2}$ a functionalized analogue of $\mathbf{1}$ that preserved the integrity of the four phosphonate groups.

It was later found that conjugation of the bifunctional ligand to the PAMAM dendrimer was more efficient if the protected ester ligand 7 was used instead of the free acid. Reduction of the nitro group with hydrogen and palladium catalyst afforded the corresponding amine $\mathbf{8}$ in $72 \%$ yield (Scheme 3). The amine was then converted to the isothiocyanate 9 by reaction with thiophosgene in a biphasic reaction at $\mathrm{pH}$ 2. The isothiocyanate group is ideal for conjugation with primary amines, such as those that decorate the surface of the PAMAM dendrimer, under mild conditions. The phosphonate ester was preferred for this conjugation reaction in order to minimize non-reactive salt formation between the amines of the dendrimer and phosphonic acids and repulsion between conjugated and incoming phosphonates. The ethylenediamine core G5-PAMAM dendrimer selected as the basis of our macromolecular construct has 128 primary amine groups on its surface. The dendrimer was reacted with 256 equivalents of 9 for $24 \mathrm{~h}$ at $40{ }^{\circ} \mathrm{C}$ followed by a further 256 equivalents for $48 \mathrm{~h}$. The reaction $\mathrm{pH}$ was maintained at 9 throughout by addition of a $1 \mathrm{M}$ solution of $\mathrm{NaOH}$. The reaction was analysed by HPLC using a Phenomenex BIOSEP SEC S-3000 size exclusion column (5-700 kD, PBS buffer, pH 7.4). The chelate-dendrimer conjugate was purified by repeated diafiltration using a Centricon C-30 membrane with a $30 \mathrm{kD}$ cut-off (Millipore) until no low molecular weight materials could be detected by HPLC. HPLC analysis of the resulting dendrimer indicated that an average hydrodynamic volume equating to a molecular weight of about $140 \mathrm{kD}$ was achieved. This corresponds to an average of $75 \%$ coverage or 96 ligands per dendrimer. A ligand/dendrimer coverage ratio of 97:1 was confirmed by elemental analysis of the carbon and sulfur content of the conjugate. Similar loading values were obtained by ${ }^{1} \mathrm{H}$ NMR analysis of the aromatic and alkyl protons, however, the reproducibility of loading values determined by this method was poorer than SEC and combustion analysis. The conjugation reaction was performed in $\mathrm{H}_{2} \mathrm{O}$, DMSO and mixtures of the two, the extent of ligand/dendrimer ratio was found to be unaffected by the choice of solvent. The phosphonate esters of the conjugate $\mathbf{1 0}$ were finally removed under identical conditions to those used in the preparation of the ligand $2, \mathrm{HBr}$ and $\mathrm{AcOH}$, to afford the conjugate $\mathbf{1 1}$. 
Formation of the gadolinium complexes of $\mathbf{2}$ and $\mathbf{1 1}$ also requires special attention. With most DOTA-tetraamide ligands, this step is relatively simple; however, we have recently reported that the phosphonate groups of $\mathbf{1}$ can interfere with these complexation reactions[12] so care was taken to perform the complexation reactions of both $\mathbf{2}$ and $\mathbf{1 1}$ at $\mathrm{pH} 9$ in order to ensure that the gadolinium ion was bound by the macrocyclic coordination cage. In the case of ligand 2 equimolar amounts of ligand and gadolinium chloride hexahydrate were reacted together at $\mathrm{pH} 9$ and $60^{\circ} \mathrm{C}$ in aqueous solution. No further purification was undertaken. However, 1.2 equivalents of gadolinium chloride were used in the reaction with $\mathbf{1 1}$ to ensure complete reaction of the ligands. After $48 \mathrm{~h}$ at $40^{\circ} \mathrm{C}$ and $\mathrm{pH} 9$ in aqueous solution the excess gadolinium was removed by addition of EDTA followed by dialysis in water $(12 \mathrm{kD}$ molecular weight cutoff, Sigma Aldrich). The conjugate Gd11 was then further purified by diafiltration with Centricon $\mathrm{C}-10$ (10 kD cut-off) in water at $\mathrm{pH}$ 7.4. Although addition of the $\mathrm{Gd}^{3+}$ ion into each ligand of the conjugate would lead to a substantial increase in molecular weight, this increase would be expect to have little or no effect upon the hydrodynamic volume of the conjugate. Thus, size exclusion HPLC was used to verify that the apparent molecular weight remained near $140 \mathrm{kD}$.

\section{Relaxometric studies}

The relaxivity $\mathrm{pH}$ profile of $\mathrm{Gd} \mathbf{2}$ was recorded and compared with that of $\mathrm{Gd} \mathbf{1}$ to ensure that the introduction of the benzylic function on the macrocyclic ring did not negatively impact the $\mathrm{pH}$ responsive properties of the complex. The relaxivity $\mathrm{pH}$ profiles of $\mathrm{Gd} \mathbf{1}$ and $\mathrm{Gd} \mathbf{2}$ (Figure 2) are comparable, rising and falling to approximately the same relaxivity at approximately the same $\mathrm{pH}$. The only slight difference between the two profiles is that the relaxivity of $\mathrm{Gd} \mathbf{2}$ is slightly higher than that of $\mathrm{Gd} \mathbf{1}$ between $\mathrm{pH} 4$ and 6 . This may be a reflection of slight changes in the protonation constants of the phosphonates, but nonetheless indicates that introduction of the nitrobenzyl substituent does not negatively impact the behaviour of Gd2. Like Gd1 the relaxivity of $\mathrm{Gd} \mathbf{2}$ changes over a physiologically relevant $\mathrm{pH}$ range. The relaxivity $\mathrm{pH}$ profile of Gd11 is also shown (Figure 2); here the advantage of conjugating the low molecular weight chelate to a dendrimer is immediately apparent. The relaxivity of Gd11 changes over the same physiologically relevant $\mathrm{pH}$ range as that of $\mathrm{Gd} 1$ and $\mathrm{Gd} 2$ but is much higher on a per $\mathrm{Gd}^{3+}$ basis, rising from $10.8 \mathrm{~mm}^{-1} \mathrm{~s}^{-1}$ at $\mathrm{pH} 9.5$ to $24.0 \mathrm{~mm}^{-1} \mathrm{~s}^{-1}$ at $\mathrm{pH}$ 6. (On a per molecule basis relaxivity rises from $1037 \mathrm{~mm}^{-1} \mathrm{~s}^{-1}$ to $2304 \mathrm{~mm}^{-1} \mathrm{~s}^{-1}$.) This equates to a relaxivity $\mathrm{pH}$ response, $\Delta r_{1}$, of $122 \%$ on passing from $\mathrm{pH} 9.5$ to 6.0 , more than doubling the $\Delta r_{1}$ of $\mathrm{Gd} \mathbf{1}$ and $\mathrm{Gd} 2$, $\Delta r_{1}=51$ and 59\%, respectively, over the same $\mathrm{pH}$ range. Although the $\mathrm{pH}$ profiles of $\mathrm{Gd} 1$ and $\mathrm{Gd} 2$ exhibit a drop in relaxivity on passing below pH 6 the profile of Gd11 cannot be measured below this $\mathrm{pH}$ since the dendrimer conjugate precipitates from solution immediately below $\mathrm{pH}$ 5.9. This is presumably the result of the high molecular weight conjugate suddenly reaching its isoelectric point.

The difference in relaxivity between the "on" (pH 6) and "off" (pH 9.6) states of the dendrimerbased $\mathrm{pH}$ responsive agent was improved by more than a factor of 2 by slowing molecular rotation. This should render the dendrimer-conjugate, $\mathrm{Gd11}$, a more effective $\mathrm{pH}$ responsive agent for imaging tissue $\mathrm{pH}$. In order to assess the origins of this improvement in $\mathrm{pH}$ responsive behaviour, nuclear magnetic resonance dispersion (NMRD) profiles of Gd11 were recorded at high and low $\mathrm{pH}$ values (Figure 3). At both $\mathrm{pH} 6.5$ and at $\mathrm{pH} 9.3$, the relaxivity increased at lower temperatures indicating that the observed relaxivities are not limited by slow water proton exchange between complex and bulk water. Comparing the high field (1-100 MHz) regions of NMRD profiles recorded at the same temperature we can see that at higher $\mathrm{pH}$ (9.3) the curve is flatter and has a lower magnitude than at lower $\mathrm{pH}(6.5)$. This indicates that at $\mathrm{pH}$ 9.3 the effective correlation time, $\tau_{\mathrm{C}}$, which is responsible for modulating relaxation, is shorter than it is at $\mathrm{pH} 6.5$. 
Owing to the large number of ionizable phosphonate and dendrimer amine groups on the dendrimer, multiple protonated species must exist at each $\mathrm{pH}$ value. This complicates any attempt to "fit" these NMRD profiles in a quantitative, meaningful way. Nonetheless, it is useful examine the parameters that influence relaxivity in a qualitative sense in order to probe which factors are responsible for the observed behaviour. One may assume that each of the 96 $\mathrm{Gd}^{3+}$ chelates on the dendrimer surface has one water molecule in its inner coordination sphere. In addition, the phosphonate groups of each pendant arm may form hydrogen-bonding interactions with nearby water molecules forming a second hydration sphere. The extent of this second hydration sphere is likely to vary as the phosphonates are protonated or deprotonated with changing $\mathrm{pH}$. Over a certain $\mathrm{pH}$ range it has also been shown that these phosphonates can catalyse exchange of protons from the coordinated water molecule to the bulk solvent.[12] Finally there is an outer-sphere contribution to relaxivity resulting from the diffusion water molecules of the bulk solvent close by the slowly tumbling $\mathrm{Gd}^{3+}$ chelates. This outer-sphere effect depends primarily on the rate of diffusion of water and is insensitive to changes in $\mathrm{pH}$.

Conjugating $\mathrm{Gd}^{3+}$ complexes to dendrimers is a common strategy for slowing the rotational dynamics of paramagnetic complexes.[30-37] In order to quantitatively describe the rotational dynamics of these dendrimer systems, the Lipari-Szabo approach is typically used.[38-43] This model employs two correlation times; a long correlation time that defines the global motion of the entire dendrimer conjugate, $\tau_{\mathrm{g}}$, and a second shorter correlation time, $\tau_{\mathrm{l}}$, that reflects the local motion of the metal complex about its point of attachment to the dendrimer. This fast local motion is superimposed upon the slower global motion of the dendrimer. For systems conjugated to G5-PAMAM dendrimers the global correlation time, $\tau_{\mathrm{g}}$, has been reported on the order of $4-5 \mathrm{~ns}$.[42,44] The correlation time describing the local motion, $\tau_{1}$, of the complex range from $0.07-0.76 \mathrm{~ns}$.[41-44] The relative weighting of these two correlation times is given by an order parameter, $S^{2}$, that can range from 0 (where local motion is dominant) to 1 (where isotropic, global motion is dominant). For dendrimers modified with $\mathrm{Gd}^{3+}$ chelates $S^{2}$ was found to range from $0.28-0.5$.

We assumed that similar rotational dynamics applied to Gd11 and these parameters to simulate the high field region (1-100 MHz) of an NMRD profile (Figure 4). Electron-spin relaxation parameters were fixed at values similar to those used elsewhere.[40-44] When the rate of proton exchange between water molecules associated with the complex (either 1st or 2nd hydration sphere) and the bulk solvent is extremely fast ( $\operatorname{short} \tau_{M}$ ) the high field NMRD profile is flat and relaxivity low (Figure 4a). This is because these protons have a low probability of being relaxed before they exchange back into the bulk solvent. At the other extreme, very slow exchange that is, very long $\tau_{\mathrm{M}}$, the profile is also flat and relaxivity low (Figure $4 \mathrm{~b}$ ) because these protons, once relaxed by $\mathrm{Gd}^{3+}$, remain on the complex preventing others from being relaxed. So in both cases relaxation is not effectively transferred to the bulk solvent and the $T_{1}$ of the bulk remains long. Between these two extremes, where $1 \mathrm{~ns}<\tau_{\mathrm{M}}<1000 \mathrm{~ns}$, the profile is characterized by higher relaxivities and a "hump" between 10 and $60 \mathrm{MHz}$ (Figure 4). The magnitude of the relaxivity in the profiles will depend on these exchange kinetics, but also on the number of exchangeable protons and their distance from $\mathrm{Gd}^{3+}$. However, these latter two parameters will not affect the shape of the NMRD profile.

In order to mimic the flat, field independent behaviour observed for $\mathrm{Gd} 11$ at $\mathrm{pH} 9.3$, the proton residence lifetime, $\tau_{\mathrm{M}}$, must be either very short $(<1 \mathrm{~ns})$ or very long $(>1 \mu \mathrm{s})$. The rate of water proton exchange is temperature dependent; as the temperature is lowered $\tau_{\mathrm{M}}$ becomes longer. This increase in $\tau_{M}$ applies to both water molecules in the inner and second hydration spheres; however, it has an opposing effect on the relaxivity of each. The water protons of the innersphere water molecule of Gd1 were found to be in slow exchange with the bulk,[12] and so these protons contribute poorly to the overall relaxivity. In contrast, water protons of a second 
hydration sphere are known to undergo very rapid exchange that also limits their contribution to relaxivity.[22] Whereas making $\tau_{\mathrm{M}}$ of the inner sphere longer (lower temperature) will not result in an increase in relaxivity, making $\tau_{M}$ of the second sphere longer could bring these protons into a range where they are able to contribute more substantially to relaxivity (Figure 4a). Inspecting the NMRD profile of Gd11 recorded at $\mathrm{pH} 9.3$ and $35^{\circ} \mathrm{C}$, the high field region is flat suggesting that exchange of inner-sphere water protons is too slow and exchange of second sphere water protons too fast for a relaxivity enhancement "hump" to be observed at high field. As the temperature is taken down to $5^{\circ} \mathrm{C}$ the profile begins to take on the appearance of a small "hump" at high field. Clearly exchange from the inner-sphere water protons will continue to be too slow to provide a contribution to relaxivity at lower temperatures. The small increase in relaxivity must therefore be the result of slowing the exchange rate of second-sphere water protons into a range that allows some contribution to relaxivity. This second-sphere contribution to relaxivity is not observed for either $\mathrm{Gd} \mathbf{1}$ or $\mathrm{Gd} \mathbf{2}$ because their rotational dynamics are too rapid. Given the small size of the high field relaxivity hump, exchange of second-sphere water molecules is likely to be in the range of $\tau_{\mathrm{M}}=0.5-5 \mathrm{~ns}$.

Over a certain $\mathrm{pH}$ range, the phosphonate groups of the pendant arms of the low molecular weight complexes $\mathrm{Gd} \mathbf{1}$ and $\mathrm{Gd} \mathbf{2}$, catalyse exchange of inner-sphere water protons with the bulk solvent.[12] The fast rotational dynamics ( $\tau_{\mathrm{g}} \approx 0.1 \mathrm{~ns}$ ) of these low molecular weight chelates limits their relaxivity but conjugation to the dendrimer lifts this restriction in $\mathrm{Gd} \mathbf{1 1}$ and so the observed relaxivity is higher by a factor of almost 5 . At $\mathrm{pH} 6.5$ and $35^{\circ} \mathrm{C}$ the NMRD profile of Gd11 already has a slight high field "hump" which becomes more pronounced as the temperature is lowered. From studies on Gd1, a contribution to this high field relaxivity from the inner-sphere proton exchange is expected. However, a contribution from protons in the second hydration sphere is also apparent. This is most clearly seen when the temperature is lowered. The $\tau_{\mathrm{M}}$ of inner-sphere water protons of Gd1 was found to be on the order of microseconds[12] and so as the temperature is lowered the inner-sphere relaxivity should decrease as exchange becomes increasingly limited (cf. Figure 4b). The observed relaxivity increases with decreasing temperature indicating that a substantial second-sphere component must be present (Figure 4a). The fact that the increase in high field relaxivity with decreasing temperature is larger at $\mathrm{pH} 6.5$ than it is at $\mathrm{pH} 9.3$ suggests that either the second hydration sphere is larger or it is more ordered, leading to longer $\tau_{\mathrm{M}}$ values, at $\mathrm{pH} 6.3$ than at 9.3. Gd11 would seem to be a rare example of a system in which relaxivity is limited both by prototropic exchange in the 2 nd-sphere that is too fast and by water exchange in the innersphere that is too slow.

It is worth noting that a third factor may also play a role in improving the relaxivity $\mathrm{pH}$ response of $\mathrm{Gd11} . \mathrm{Gd}^{3+}$ complexes that exhibit no $\mathrm{pH}$ response have been found to behave as $\mathrm{pH}$ responsive agents once conjugated to PAMAM dendrimers.[44] The origin of this phenomenon is thought to be changes in the internal motion of the dendrimer itself as the $\mathrm{pH}$ changes. Protonation of amines within the body of the dendrimer is believed to make the dendrimer more rigid making $\tau_{\mathrm{R}}$ longer at lower $\mathrm{pH}$. Thus the relaxivity of agents conjugated to these dendrimers has been found to increase as the $\mathrm{pH}$ drops. It is likely that, in addition to the interplay of inner-sphere and second-sphere water proton exchange rates, a third contribution to the $\mathrm{pH}$ responsive behaviour of $\mathrm{Gd} \mathbf{1 1}$ arises from changes in the rigidity of the dendrimer with changes in $\mathrm{pH}$.

\section{Conclusions}

It is possible to take advantage of the interplay between molecular reorientation and water proton exchange kinetics to enhance the response behaviour of complexes that exhibit changes in relaxivity arising from changes in water or proton exchange kinetics. Our initial hypothesis was that coupling the $\mathrm{pH}$-responsive agent $\mathrm{Gd} \mathbf{1}$ to a dendrimer would increase both the overall 
relaxivity, $r_{1}$, the responsiveness of relaxivity to $\mathrm{pH}, \Delta r_{1}$. This was achieved by slowing rotation via conjugation to a dendrimer, increasing $\Delta r_{1}$ by more than a factor of 2 . This enhancement should enable Gd11 to serve as an effective $\mathrm{pH}$ responsive MRI contrast agent. Furthermore, this dendrimer system has provided further insights into the mechanism by which this class if $\mathrm{pH}$ responsive agent, $\mathrm{Gd} \mathbf{1}, \mathrm{Gd} \mathbf{2}$ and $\mathrm{Gd} \mathbf{1 1}$, operates. The $\mathrm{pH}$ response is the result of a complex interplay between the rate of proton exchange between the bulk solvent and water molecules in the inner and second hydration spheres. The overall relaxivity is ultimately limited by the slow exchange kinetics of protons in the inner hydration sphere and rapid exchange kinetics of protons in the second hydration sphere. From an imaging point of view the substantial improvements in both $r_{1}$ and $\Delta r_{1}$ afforded by Gd11 should allow improved determination of in vivo $\mathrm{pH}$ by MRI. However, it is worth noting that improving $\Delta r_{1}$ through increased molecular weight may also negatively impact the effectiveness of such agents. Large molecules, such as dendrimers, remain in vasculature longer than discrete agents, such as Gd1, which are better able to diffuse into all extracellular space. Furthermore, large molecules, such as Gd11, tend to clear more slowly from the body as a result of increased liver uptake. This extends the retention time of $\mathrm{Gd}^{3+}$ in the body. Further studies into the in vivo behaviour of dendrimer-based MRI contrast media will be required to establish if this approach, which is successful for increasing both $r_{1}$ and $\Delta r_{1}$, will yield agents that can actually be applied in vivo.

\section{Experimental Section}

\section{General remarks}

All reagents and solvents were purchased from commercial sources and used as received unless otherwise stated. The ethylene core G5-PAMAM dendrimer from Dendritech was purchased through Sigma-Aldrich as a 5\% solution in methanol. Prior to use the solvents were removed under vacuum and the dendrimer redissolved in the reaction solvent. ${ }^{1} \mathrm{H}$ NMR spectra were recorded on a JOEL Eclipse 270 spectrometer operating at $270.17 \mathrm{MHz}$, a Varian Mercury 300 spectrometer operating at $299.95 \mathrm{MHz}$ and a Bruker Avance III spectrometer operating at $400.13 \mathrm{MHz} .{ }^{13} \mathrm{C}$ NMR spectra were obtained using a Bruker Avance III spectrometer operating at $100.61 \mathrm{MHz}$. Longitudinal relaxation times were measured using the inversion recovery method on a MRS-6 NMR analyzer from the Institut "Jožef Stefan", Ljubljana, Slovenjia operating at $20 \mathrm{MHz}$. The $\mathrm{pH}$ of samples for relaxivity measurements was adjusted by addition of either lithium hydroxide monohydrate or $p$-toluenesulfonic acid monohydrate in order to avoid dilution. Melting points were determined on a Fisher-Johns melting point apparatus and are uncorrected. NMRD profiles between 0.01 and $50 \mathrm{MHz}$ were recorded using the field cycling relaxometer at New York Medical Collge, Valhala NY.

\section{Synthesis}

The synthesis of diethyl phthalimidomethylphosphonate (3) and diethyl bromoacetamidomethylphosphonate (6) have been reported previously.[12]

\section{Diethyl aminomethylphosphonate (4)}

Hydrazine ( $81.6 \mathrm{~mL}, 168.2 \mathrm{mmol}$ ) was added to a solution of the phthalimide $\mathbf{3}$ (50.0 g, 1.68 $\mathrm{mol})$ in dry ethanol $(500 \mathrm{~mL})$. The reaction was stirred at room temperature for $18 \mathrm{~h}$. The solvents were removed under reduced pressure and the residue placed under high vacuum to remove as much excess hydrazine as possible. To the residue was added diethyl ether (750 $\mathrm{mL}$ ) which was then filtered to remove the precipitate. The precipitate was washed with diethyl ether $(2000 \mathrm{~mL})$. The solvents were removed from the filtrate under reduced pressure to afford the title compound as a colourless oil $(41.9 \mathrm{~g}, 97 \%)$. Characterisation data is identical to that reported previously.[12] 


\section{N',N"-Bis-(diethyl)methylphosphonate phthalamide (5)}

The title compound was isolated as a by-product of the reaction used to synthesise 4.[12] Xray quality crystals were grown by dissolving $\mathbf{5}(0.5 \mathrm{~g})$ in a minimum of dichloromethane in a $20 \mathrm{~mL}$ scintillation vial. Diethyl ether $(8 \mathrm{~mL})$ was added and the components mixed thoroughly. Hexanes $(9 \mathrm{~mL})$ were then added slowly such that a layer of hexanes lay on top of the solution of 5. The vial was sealed and the layers were allowed to diffuse together at room temperature, affording high quality crystals of 5. M.p. $119-120^{\circ} \mathrm{C} ;{ }^{1} \mathrm{H} \mathrm{NMR}\left(400 \mathrm{MHz}, \mathrm{CDCl}_{3}\right): \delta=1.21$ $\left(\mathrm{t}, 12 \mathrm{H},{ }^{3} J(\mathrm{H}, \mathrm{H})=7 \mathrm{~Hz}, \mathrm{CH}_{3}\right), 3.73\left(\mathrm{dd}, 4 \mathrm{H},{ }^{2} J(\mathrm{H}, \mathrm{P})=12 \mathrm{~Hz},{ }^{3} J(\mathrm{H}, \mathrm{H})=6 \mathrm{~Hz}, \mathrm{CH}_{2} \mathrm{P}\right), 3.98(\mathrm{q}$, $\left.4 \mathrm{H},{ }^{3} J(\mathrm{H}, \mathrm{H})=7 \mathrm{~Hz}, \mathrm{OCH}_{2}\right), 4.00\left(\mathrm{q}, 4 \mathrm{H},{ }^{3} J(\mathrm{H}, \mathrm{H})=7 \mathrm{~Hz}, \mathrm{OCH}_{2}\right), 7.36\left(\mathrm{dd}, 2 \mathrm{H},{ }^{3} J(\mathrm{H}, \mathrm{H})=6\right.$ $\left.\mathrm{Hz},{ }^{4} J(\mathrm{H}, \mathrm{H})=3 \mathrm{~Hz}, \mathrm{Ar}\right), 7.48\left(\mathrm{dd}, 2 \mathrm{H},{ }^{3} J(\mathrm{H}, \mathrm{H})=6 \mathrm{~Hz},{ }^{4} J(\mathrm{H}, \mathrm{H})=3 \mathrm{~Hz}, \mathrm{Ar}\right), 7.70 \mathrm{ppm}(\mathrm{dd}$, $\left.2 \mathrm{H},{ }^{3} \mathrm{~J}(\mathrm{H}, \mathrm{H})=6 \mathrm{~Hz}, \mathrm{NH}\right) ;{ }^{13} \mathrm{C} \mathrm{NMR}\left(100 \mathrm{MHz}, \mathrm{CDCl}_{3}\right): \delta=16.3\left({ }^{3} \mathrm{~J}(\mathrm{C}, \mathrm{P})=6 \mathrm{~Hz}, \mathrm{CH}_{3}\right), 35.2$ $\left({ }^{1} J(\mathrm{C}, \mathrm{P})=156 \mathrm{~Hz}, \mathrm{CH}_{2} \mathrm{P}\right), 62.4\left({ }^{2} J(\mathrm{C}, \mathrm{P})=6 \mathrm{~Hz}, \mathrm{OCH}_{2}\right), 128.4$ (3-Ar), 130.1 (2-Ar), 134.5 (1$\mathrm{Ar}), 168.7\left({ }^{3} J(\mathrm{C}, \mathrm{P})=5 \mathrm{~Hz}, \mathrm{C}=\mathrm{O}\right)$; IR $(\mathrm{KBr}$ disc $): v_{\max }=3251(\mathrm{NH}), 3063,2984,2931,2910$, 2236 (PO), 1661 (CO) 1595, 1539, 1479, 1444, 1369, 1319, 1217 (PO), 1163, 1098, 1023 (PO), 973, 786, $730 \mathrm{~cm}^{-1}$; ESMS-: $\mathrm{m} / z(\%): 463(100)\left[M-\mathrm{H}^{+}\right]^{-}$; elemental analysis calcd (\%) for $\mathrm{C}_{18} \mathrm{H}_{30} \mathrm{~N}_{2} \mathrm{O}_{8} \mathrm{P}_{2}$ : C 46.6, H 6.5, N 6.0; found: C 46.1, H 6.4, N 5.9.

\section{(S)-2-( $p$-Nitrobenzyl)-1,4,7,10-tetraazacyclododecane-1,4,7,10-tetraacetamidomethylene-} (diethyl)phosphonate (7)

$(S)$-2-( $p$-Nitrobenzyl) cyclen $(0.48 \mathrm{~g}, 1.56 \mathrm{mmol})$ was dissolved in acetonitrile $(20 \mathrm{~mL})$. Potassium carbonate $(1.45 \mathrm{~g}, 11.0 \mathrm{mmol})$ and bromoacetamide $6(2 \mathrm{~g}, 6.94 \mathrm{mmol})$ were added and the reaction mixture stirred for $72 \mathrm{~h}$ at $60{ }^{\circ} \mathrm{C}$. The reaction mixture was filtered and the solvents removed under reduced pressure. The residue was purified by column chromatography over silica gel eluting with $10 \%$ methanol in dichloromethane to afford the title compound as pale yellow solid $(0.53 \mathrm{~g}, 30 \%)$. ESI+: $\mathrm{m} / z(\%): 1136(35)[M+\mathrm{H}]^{+}, 1158(100)[M+\mathrm{Na}]^{+}, 1174$ (60) $[M+\mathrm{K}]^{+}$.

(S)-2-(p-Aminobenzyl)-1,4,7,10-tetraazacyclododecane-1,4,7,10-tetraacetamidomethylene(diethyl)phosphonate (8)

Nitro compound $7(0.50 \mathrm{~g}, 0.44 \mathrm{mmol})$ was dissolved in water $(15 \mathrm{~mL})$ and $10 \%$ palladium on carbon $(0.12 \mathrm{~g})$ was added. The reaction mixture was shaken on a Parr hydrogenation apparatus for $12 \mathrm{~h}$ under $\mathrm{H}_{2}(25 \mathrm{psi})$. The catalyst was removed by filtration and the solvents removed by lyophilization to afford the title compound as a colourless solid $(0.35 \mathrm{~g}, 72 \%)$. ESI+: $\mathrm{m} / \mathrm{z}$ (\%): $1106(65)[M+\mathrm{H}]^{+}, 1128(100)[M+\mathrm{Na}]^{+}$.

\section{(S)-2-(p-Isothiocyanatobenzyl)-1,4,7,10-tetraazacyclododecane-1,4,7,10- tetraacetamidomethylene-(diethyl)phosphonate (9)}

Amine $8(0.50 \mathrm{~g}, 0.45 \mathrm{mmol})$ was dissolved in water $(5 \mathrm{~mL})$ and the $\mathrm{pH}$ of the resulting solution adjusted to 2 by addition of a dilute $\mathrm{HCl}$ solution. Chloroform $(15 \mathrm{~mL})$ was added to the reaction which was then stirred vigorously at room temperature. Thiophosgene $(0.052 \mathrm{mg}, 0.45 \mathrm{mmol})$ was added to the reaction which was then stoppered and stirred vigorously for $18 \mathrm{~h}$ at room temperature. The reaction mixture was then transferred to a separatory funnel and the chloroform layer was allowed to run off. The aqueous layer was then washed with chloroform $(2 \times 20 \mathrm{~mL})$. The aqueous layer was then collected and the solvents removed under reduced pressure to afford the title compound as a colourless solid (0.48 g, 93\%). ESI+: $\mathrm{m} / z$ (\%): 1148 (100) $[M+\mathrm{H}]^{+}, 1170(78)[M+\mathrm{Na}]^{+}$.

\section{(S)-2-(p-Nitrobenzyl)-1,4,7,10-tetraazacyclododecane-1,4,7,10-tetraacet-amidomethylene phosphonic acid (2)}

Octaethyl ester $7(0.75 \mathrm{~g}, 0.66 \mathrm{mmol})$ was dissolved in a $30 \%$ solution of $\mathrm{HBr}$ in acetic acid $(8 \mathrm{~mL})$. The resulting solution was stirred at room temperature for $18 \mathrm{~h}$. The solvents were 
removed under reduced pressure and the residue taken up in EtOH $(20 \mathrm{~mL})$, the solvents were again removed under reduced pressure. The solid residue was then taken up into $\mathrm{MeOH}$ (10 $\mathrm{mL}$ ) and the title compound precipitated by dropwise addition of $\mathrm{Et}_{2} \mathrm{O}$. The title compound was isolated by filtration, dissolved in water and the solvents removed by lypholization to afford a tan solid $(0.49 \mathrm{~g}, 81.4 \%)$. ESI+: $\mathrm{m} / z(\%): 511(100)\left[\mathrm{H}_{4} \mathrm{~L}+5 \mathrm{Na}\right]^{2+}$.

\section{G5-PAMAM dendrimer-ligand phosphonate diethyl ester conjugate (10)}

G5-PAMAM dendrimer (40 mg, $1.4 \mu \mathrm{mol}$ ) was dissolved in DMSO/water 1:1 $(4 \mathrm{~mL})$. Isothiocyanate $9(0.41 \mathrm{~g}, 0.36 \mathrm{mmol})$ was added and the $\mathrm{pH}$ of the resulting solution raised to 9 by addition of $1 \mathrm{~m} \mathrm{NaOH}$ solution. The reaction was then stirred at $40{ }^{\circ} \mathrm{C}$ for $24 \mathrm{~h}$ with the $\mathrm{pH}$ maintained at 9 by addition of $\mathrm{NaOH}$ before a solution of $9(0.41 \mathrm{~g}, 0.36 \mathrm{mmol})$ in DMSO (1 $\mathrm{mL}$ ) was added. The reaction was stirred for a further $48 \mathrm{~h}$ at $\mathrm{pH} 9$. The reaction mixture was then transferred to a Centircon C-30 diafiltration cell with a $30 \mathrm{kD}$ molecular weight cut-off. Diafiltration was repeated until SEC-HPLC revealed that no further low molecular weight material was present, the solvents were then removed by lyophylisation to afford a colourless solid $(0.11 \mathrm{~g})$. Anal found C 28.63 , S $1.34 \%$, or 56.975 carbon atoms per sulfur atom. The ligand formula $\mathrm{C}_{44} \mathrm{H}_{81} \mathrm{~N}_{9} \mathrm{O}_{16} \mathrm{P}_{4} \mathrm{~S}$ equates to 1 ligand per 12.975 carbon atoms of the dendrimer. The dendrimer formula $\mathrm{C}_{1262} \mathrm{H}_{2528} \mathrm{~N}_{506} \mathrm{O}_{252}$ affords a ratio $1262 / 12.975$ or 97.26 ligands per dendrimer.

\section{G5-PAMAM dendrimer-ligand phosphonic acid conjugate (11)}

Conjugate $10(0.11 \mathrm{~g})$ was dissolved in a $30 \%$ solution of $\mathrm{HBr} /$ glacial acetic acid $(3 \mathrm{~mL})$ under an argon atmosphere. The reaction was stirred at room temperature for $18 \mathrm{~h}$. The solvents were then removed under reduced pressure and residue taken up into methanol $(10 \mathrm{~mL})$ which was then also removed under reduced pressure. Dissolution and evaporation of methanol was performed a further three times to removes as much excess acetic acid as possible. The residue was then washed with diethyl and vacuum dried to afford the title compound as a colourless solid $(0.09 \mathrm{~g})$.

\section{SEC-HPLC analysis}

Size-exclusion HPLC analysis of $\mathbf{1 0}$ and Gd11 were performed on a phenomenex BIOSEP SEC S-3000 size exclusion column (5-700 kD) eluting with PBS buffer at pH 7.4. The column was standardised using commercially available protein (globular) molecular weight standards: cytochrome C (12.4 kD), carbonic anhydrase $(29 \mathrm{kD})$, bovine serum albumin $(66 \mathrm{kD}), \gamma$ globulins (160 kD), apoferritin (480 kD), dextran blue (2000 kD).

\section{Crystal structure determination of 5}

Data collection-A colourless irregular block with approximate orthogonal dimensions $0.46 \times 0.41 \times 0.25 \mathrm{~mm}$ was placed and optically centered on the Bruker SMART1000 CCD system (Bruker, SMART, Version 5.054 (2004) and SAINT, Version 7.23 A, Bruker AXS Inc.) at $-183{ }^{\circ} \mathrm{C}$. The initial unit cell was indexed using a least-squares analysis of a random set of reflections collected from three series of $0.3^{\circ}$ wide $\omega$ scans, 10 seconds per frame, and 25 frames per series that were well distributed in reciprocal space. Five $\omega$-scan data frame series were collected $\left(\mathrm{Mo}_{\mathrm{Ka}}\right)$ with $0.3^{\circ}$ wide scans, 20 seconds per frame and 606 frames collected per series at varying $\phi$ angles $\left(\phi=0,72,144,216,288^{\circ}\right)$. The crystal to detector distance was $4.123 \mathrm{~cm}$, thus providing a complete sphere of data to $2 \theta_{\max }=60.48^{\circ}$.

Structural determination and refinement-A total of 88185 reflections were collected and corrected for Lorentz and polarization effects and absorption using Blessing's method [45] as incorporated into the program SADABS (Sheldrick, G.M., SADABS, Version 2.10 (2003), "Siemens Area Detector Absorption Correction” Universität Göttingen, Göttingen, 
Germany) with 13581 unique. The SHELXTL (G. M. Sheldrick, SHELXTL, Version 6.1, 2002, Bruker AXS Inc.) program package was implemented to determine the probable space group and set up the initial files. System symmetry, systematic absences, and intensity statistics indicated the non-centrosymmetric orthorhombic space group Pna2 $2_{1}$ (no. 33). The structure was determined by direct methods with the successful location of a majority of the molecule within the asymmetric unit using the program XS (G. M. Sheldrick, SHELXS97 and SHELXL97, 1997), which was also used to refine the structure. The data collected were merged based upon identical indices yielding 53260 data $[R(\mathrm{int})=0.0267]$ that were truncated to $2 \theta_{\max }=60.00^{\circ}$ resulting in 51060 data that were further merged during least-squares refinement to 13322 unique data $[R(\mathrm{int})=0.0393]$. A series of least-squares difference-Fourier cycles were required to locate the remaining non-hydrogen atoms and optimize the various disorders present for the two molecules in the asymmetric unit. All full occupancy non-hydrogen atoms were refined anisotropically. Hydrogen atoms were idealized throughout the final refinement stages. The final structure was refined to convergence with $R(F)=6.55 \%, w R\left(F^{2}\right)=12.39 \%$, $\mathrm{GOF}=1.118$ for all 13322 unique reflections $\left[R(F)=5.72 \%, w R\left(F^{2}\right)=12.02 \%\right.$ for those 11744 data with $\left.F_{\mathrm{o}}>4 \sigma\left(F_{\mathrm{o}}\right)\right]$. The final difference-Fourier map was featureless indicating that the structure is both correct and complete. An empirical correction for extinction was also attempted but found to be negative and therefore not applied. The absolute structure parameter, Flack $(x),[46]$ was refined and found to be $0.38(9)$ indicating that racemic twinning is present.

CCDC 680275 (5) contains the supplementary crystallographic data for this paper. These data can be obtained free of charge from The Cambridge Crystallographic Data Centre via www.ccdc.cam.ac.uk/data_request/cif.

\section{Supplementary Material}

Refer to Web version on PubMed Central for supplementary material.

\section{Acknowledgements}

The authors thank the National Institutes of Health (RR-02584, CA-126608 and CA-115531), the Robert A. Welch Foundation (AT-584) for financial assistance.

\section{References}

1. Wike-Hooley JL, Haveman J, Reinhold JS. Radiother. Oncol 1984;2:343. [PubMed: 6097949]

2. Tannock IF, Rotin D. Cancer Res 1989;49:4373. [PubMed: 2545340]

3. Vaupel P, Kallinowski F, Okunieff P. Cancer Res 1989;49:6449. [PubMed: 2684393]

4. Khramtsov VV. Curr. Org. Chem 2005;9:909.

5. Woods, M.; Zhang, S.; Kovacs, Z.; Sherry, AD. Advances in Supra-molecular Chemistry. Gokel, G., editor. Vol. Vol. 9. Amsterdam: Elsevier; 2003. p. 1 and references therein

6. Aime S, Castelli DD, Terreno E. Angew. Chem 2002;114:4510.Angew. Chem. Int. Ed 2002;41:4334.

7. Aime S, Barge A, Castelli DD, Fedeli F, Mortillaro A, Nielsen FU, Terreno E. Magn. Reson. Med 2002;47:639. [PubMed: 11948724]

8. Woods M, Zhang S, Von Howard E, Sherry AD. Chem. Eur. J 2003;9:4634.

9. Terreno E, Castelli Daniela D, Cravotto G, Milone L, Aime S. Invest. Radiol 2004;39:235. [PubMed: 15021328]

10. Woods M, Kiefer GE, Bott S, Castillo-Muzquiz A, Eshelbrenner C, Michaudet L, McMillan K, Mudigunda SDK, Ogrin D, Tircso G, Zhang S, Zhao P, Sherry AD. J. Am. Chem. Soc 2004;126:9248. [PubMed: 15281814]

11. Aime S, Fedeli F, Sanino A, Terreno E. J. Am. Chem. Soc 2006;128:11326. [PubMed: 16939235]

12. Kalman FK, Woods M, Caravan P, Jurek P, Spiller M, Tircso G, Kiraly R, Brucher E, Sherry AD. Inorg. Chem 2007;46:5260. [PubMed: 17539632] 
13. Zhang S, Wu K, Sherry AD. Angew. Chem 1999;111:3382.Angew. Chem. Int. Ed 1999;38:3192.

14. Bloembergen N. J. Chem. Phys 1957;27:572.

15. Bloembergen N, Morgan LO. J. Chem. Phys 1961;34:842.

16. Bloembergen N, Purcell EM, Pound RV. Phys. Rev 1948;73:679.

17. Solomon I. Phys. Rev 1955;99:559.

18. Solomon I, Bloembergen N. J. Chem. Phys 1956;25:261.

19. Garcia-Martin ML, Martinez GV, Raghunand N, Sherry AD, Zhang S, Gillies RJ. Magn. Reson. Med 2006;55:309. [PubMed: 16402385]

20. Raghunand N, Howison C, Sherry AD, Zhang S, Gillies RJ. Magn. Reson. Med 2003;49:249. [PubMed: 12541244]

21. Raghunand N, Zhang S, Sherry AD, Gillies RJ. Acad. Radiol 2002;9:S481. [PubMed: 12188315]

22. Borel A, Helm L, Merbach AE. Chem. Eur. J 2001;7:600.

23. Botta M. Eur. J. Inorg. Chem 2000:399.

24. Ing HR, Manske RHF. J. Chem. Soc 1926:2348.

25. Khan MN, Ohayagha JE. React. Kinet. Catal. Lett 1996;42:97.

26. Khan MN. J. Org. Chem 1996;61:8063. [PubMed: 11667789]

27. Ariffin A, Khan MN, Lan LC, May FY, Yun CS. Synth. Commun 2004;34:4439.

28. Khan MN. J. Org. Chem 1995;60:4536.

29. Curley OMS, McCormick JE, McElhinney RS, McMurry TBH. ARKIVOC 2003:180.

30. Wang SJ, Brechbiel M, Wiener EC. Invest. Radiol 2003;38:662. [PubMed: 14501494]

31. Wiener E, Narayanan VV. Adv. Dendritic Macromol 2002;5:129.

32. Konda SD, Aref M, Brechbiel M, Wiener EC. Invest. Radiol 2000;35:50. [PubMed: 10639036]

33. Wiener EC, Konda S, Shadron A, Brechbiel M, Gansow O. Invest. Radiol 1997;32:748. [PubMed: 9406015]

34. Wiener EC, Brechbiel MW, Gansow OA, Foley G, Lauterbur PC. Polym. Mater. Sci. Eng 1997;77:193.

35. Wiener EC, Auteri FP, Chen JW, Brechbiel MW, Gansow OA, Schneider DS, Belford RL, Clarkson RB, Lauterbur PC. J. Am. Chem. Soc 1996;118:7774.

36. Wiener EC, Brechbiel MW, Brothers H, Magin RL, Gansow OA, Tomalia DA, Lauterbur PC. Magn. Reson. Med 1994;31:1. [PubMed: 8121264]

37. Bryant LH Jr, Brechbiel MW, Wu C, Bulte JW, Herynek V, Frank JA. J. Magn. Reson. Imag 1999;9:348.

38. Lipari G, Szabo A. J. Am. Chem. Soc 1982;104:4546.

39. Lipari G, Szabo A. J. Am. Chem. Soc 1982;104:4559.

40. Caravan P, Parigi G, Chasse JM, Cloutier NJ, Ellison JJ, Lauffer RB, Luchinat C, McDermid SA, Spiller M, McMurry TJ. Inorg. Chem 2007;46:6632. [PubMed: 17625839]

41. Jaszberenyi Z, Moriggi L, Schmidt P, Weidensteiner C, Kneuer R, Merbach AE, Helm L, Toth E. J. Biol. Inorg. Chem 2007;12:406. [PubMed: 17216229]

42. Lebduskova P, Sour A, Helm L, Toth E, Kotek J, Lukes I, Merbach AE. Dalton Trans 2006:3399. [PubMed: 16832488]

43. Nicolle GM, Toth E, Schmitt-Willich H, Raduchel B, Merbach AE. Chem. Eur. J 2002;8:1040.

44. Laus S, Sour A, Ruloff R, Toth E, Merbach AE. Chem. Eur. J 2005;11:3064.

45. Blessing RH. Acta Crystallogr. Sect. A 1995;51:33. [PubMed: 7702794]

46. Flack HD. Acta Crystallogr. Sect. A 1983;39:876. 


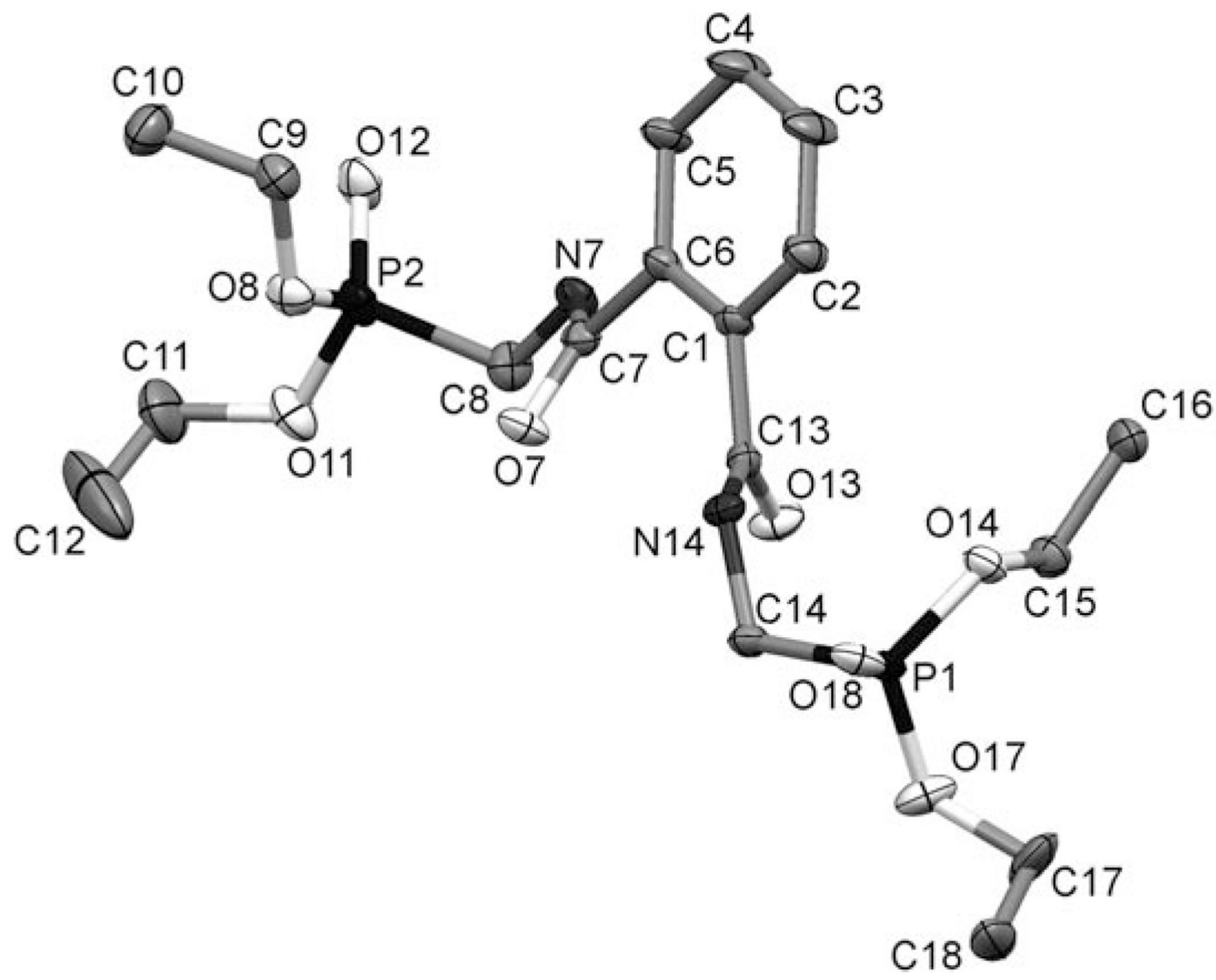

Figure 1.

ORTEP rendering of the crystal structure of $\mathbf{5}$ showing $50 \%$ ellipsoids. Hydrogen atoms have been omitted for clarity. 


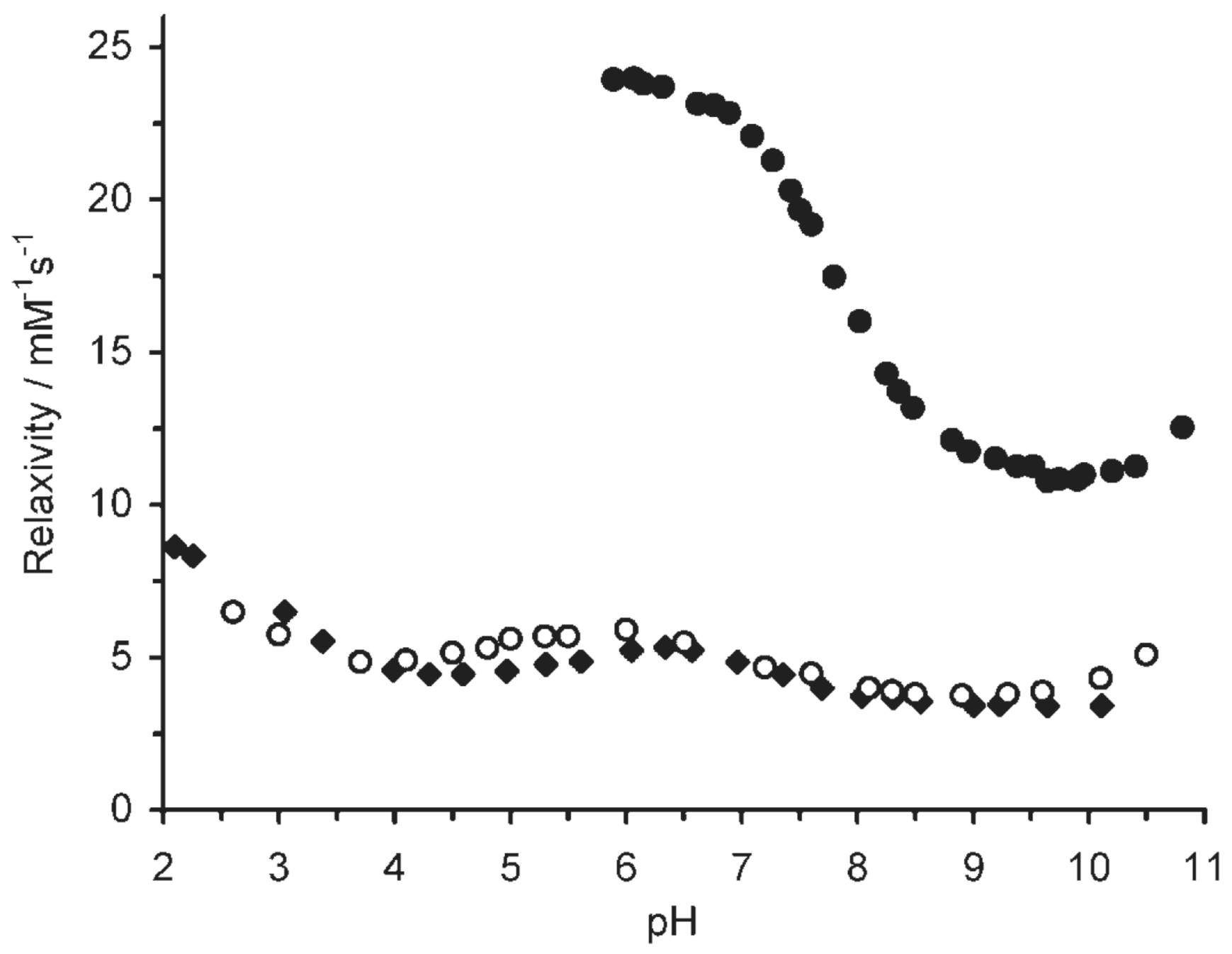

Figure 2.

Relaxivity pH profiles of $\mathrm{Gd} \mathbf{1}(\diamond)[12] \mathrm{Gd} \mathbf{2}(\circ)$ and $\mathrm{Gd} \mathbf{1 1}(\bullet)$ recorded at $20 \mathrm{MHz}$ and $298 \mathrm{~K}$.

Relaxivity is expressed per $\mathrm{Gd}^{3+}$ ion. 

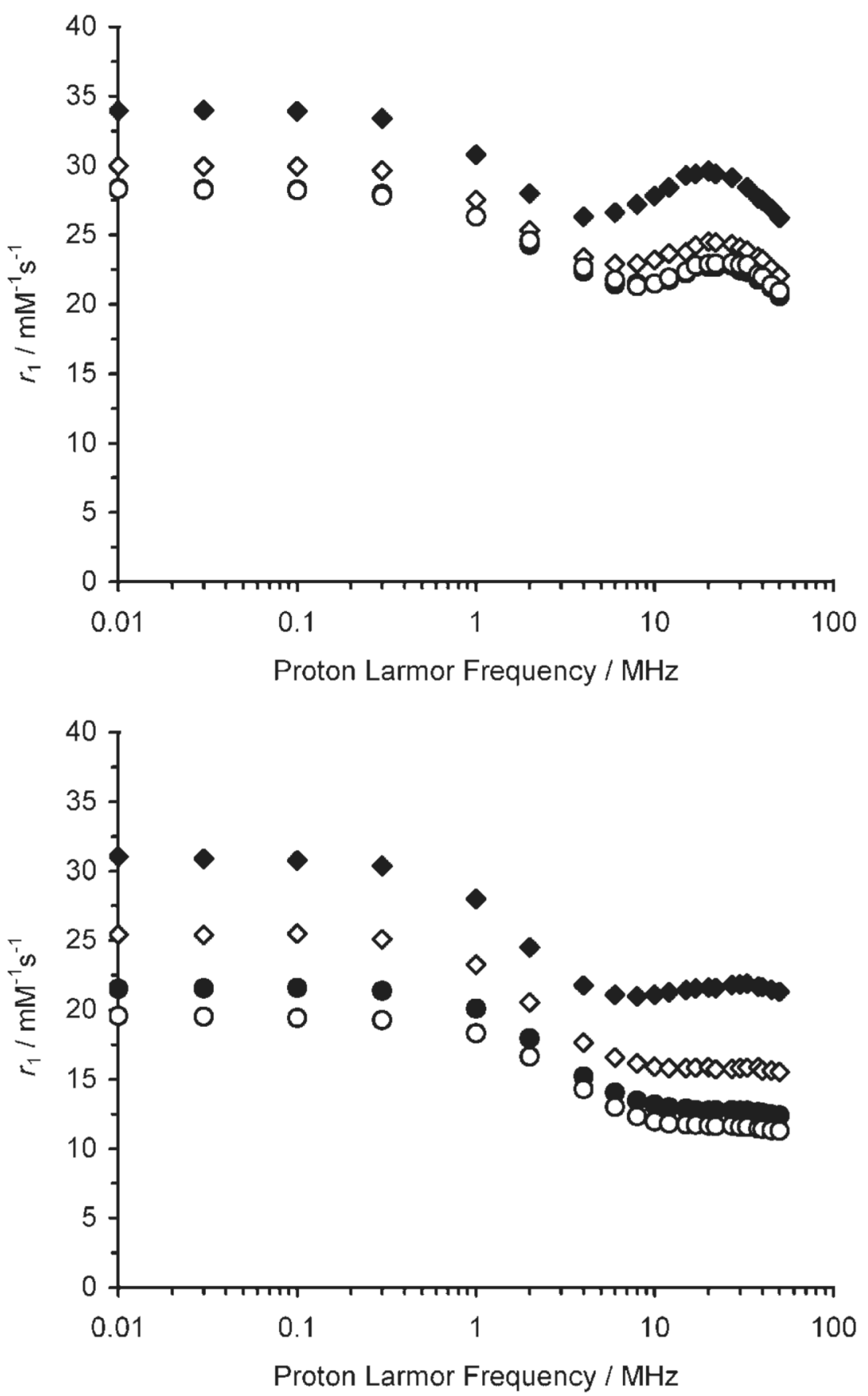

Figure 3.

NMRD profiles of Gd11 recorded at $\mathrm{pH} 6.5$ (top) and $\mathrm{pH} 9.3$ (bottom); $\diamond: 5, \diamond: 15, \bullet: 25$, o: $35^{\circ} \mathrm{C}$. 

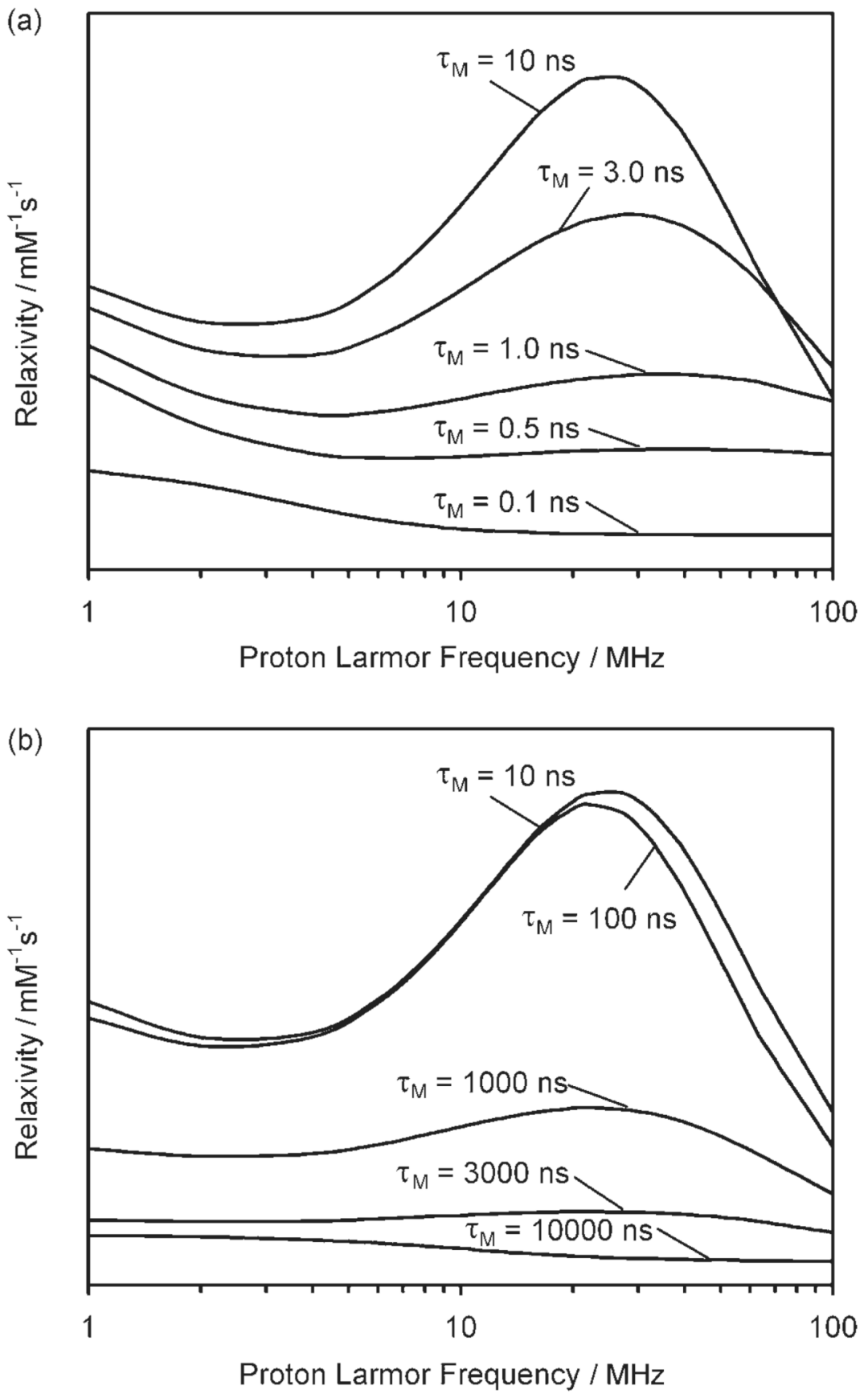

Figure 4.

Effect of proton residence lifetime $\left(\tau_{\mathrm{M}}\right)$ on the relaxivity of $\mathrm{Gd}^{3+}$-G5 PAMAM dendrimer conjugates in the fast (top) and slow (bottom) exchange regimes. The simulated profiles are plotted at same scale using parameters: $\tau_{\mathrm{g}}=4.5 \mathrm{~ns}, \tau_{\mathrm{l}}=0.15 \mathrm{~ns}, S^{2}=0.5, \tau_{\mathrm{v}}=20 \mathrm{ps}, \Delta=2 \times 10^{9} \mathrm{~s}$. 
<smiles>CC(C)COPCN1C(=O)c2ccccc2C1=O</smiles>

3<smiles>C#C[14C](=O)OCN</smiles><smiles>[R]NC(=O)CN1CCN(CC(N)=O)CCN(CC(N)=O)[C@H](Cc2ccc([N+](=O)[O-])cc2)CN1CC(N)=O</smiles>

Scheme 1.

Synthesis of a functionalised $\mathrm{pH}$ responsive contrast agent. i) $\mathrm{P}(\mathrm{OEt})_{3} / \Delta$ ii) $\mathrm{H}_{2} \mathrm{NNH}_{2} / \mathrm{EtOH}$; iii) $\mathrm{BrCH}_{2} \mathrm{COBr} / \mathrm{K}_{2} \mathrm{CO}_{3} / \mathrm{CH}_{2} \mathrm{Cl}_{2}$; iv) (S)-2-( $p$-nitrobenzyl) cyclen $/ \mathrm{K}_{2} \mathrm{CO}_{3} / \mathrm{MeCN} / 60^{\circ} \mathrm{C}$; v) $30 \% \mathrm{HBr}$ in $\mathrm{AcOH}$. 


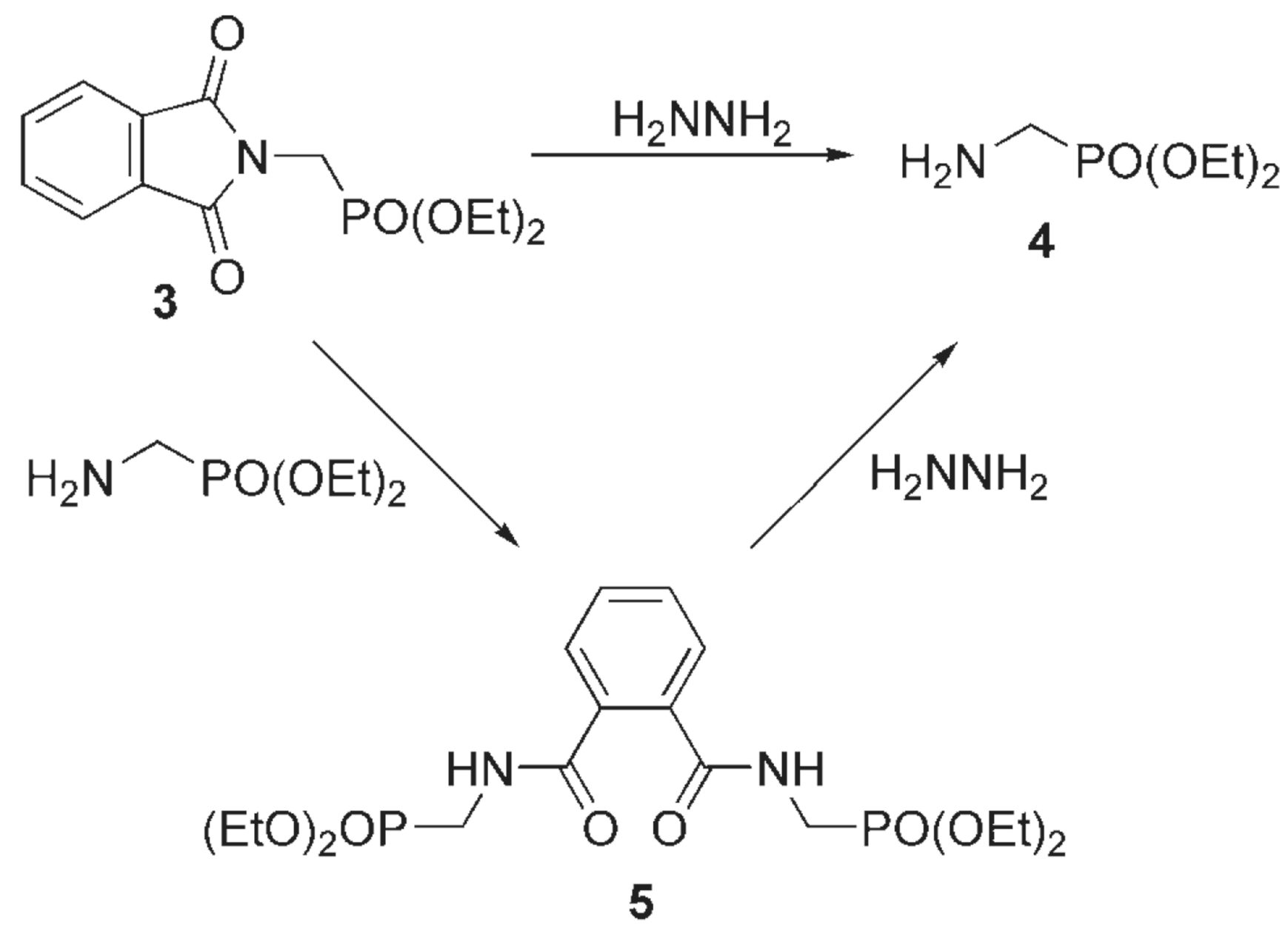

Scheme 2. 


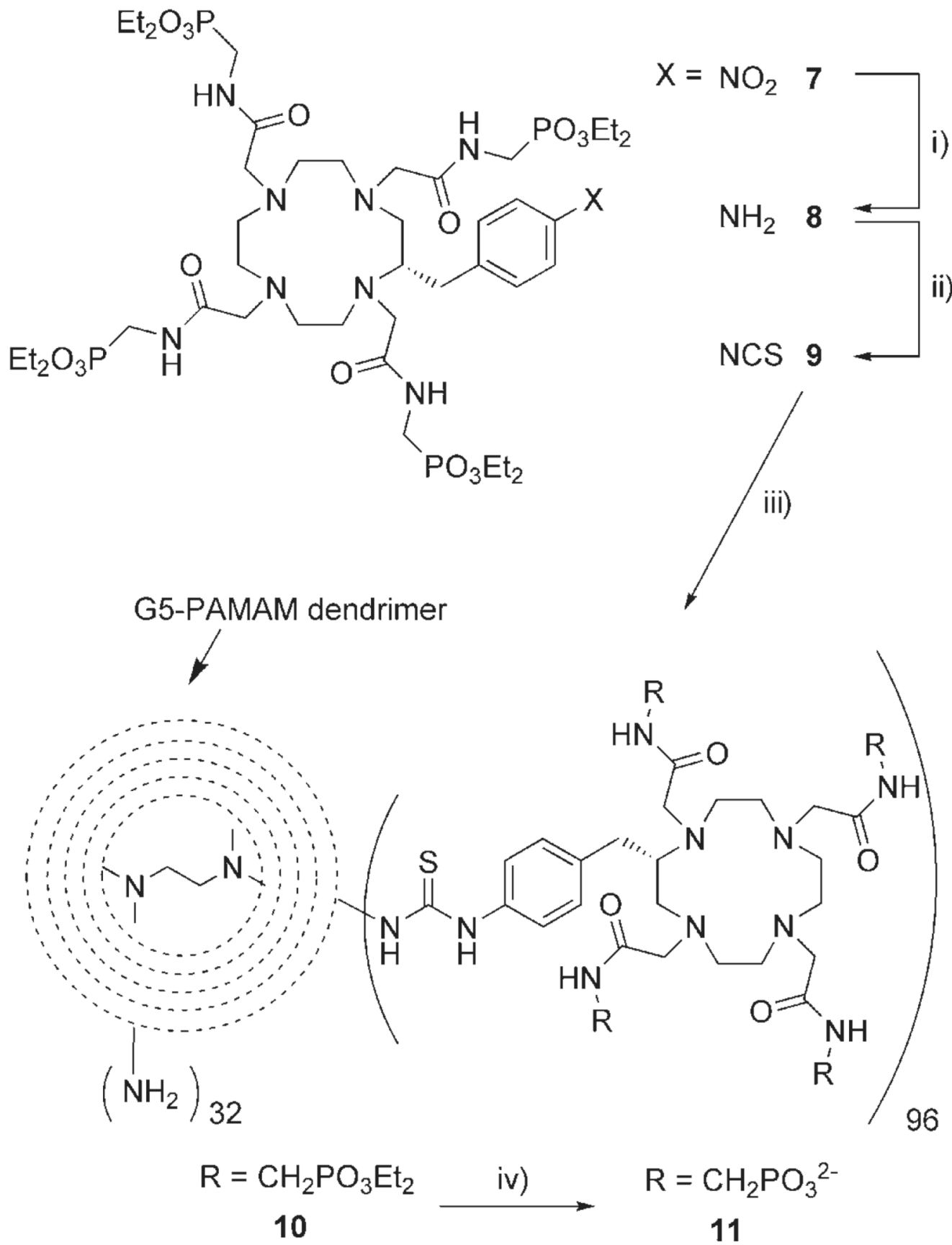

Scheme 3.

Synthesis of the dendrimer-based $\mathrm{pH}$ responsive contrast agent $\mathrm{Gd11}$. i) $\mathrm{H}_{2} / \mathrm{Pd}$ on $\mathrm{C} / \mathrm{H}_{2} \mathrm{O}$; ii) $\mathrm{SCCl}_{2} / \mathrm{CHCl}_{3} / \mathrm{H}_{2} \mathrm{O}$ pH 2; iii) G-5 PAMAM dendrimer $/ \mathrm{H}_{2} \mathrm{O} \mathrm{pH} 8$; iv) $30 \% \mathrm{HBr}$ in $\mathrm{AcOH}$. 